\title{
DETERMINATION OF SEAKEEPING PERFORMANCE FOR A CASE STUDY VESSEL BY THE STRIP THEORY METHOD
}

\author{
Karol Niklas \\ Artur Karczewski \\ Gdańsk University of Technology, Poland
}

\begin{abstract}
The increase of seakeeping performance is of particular importance for car and passenger ferries, service ships in the gas and oil extraction industry and offshore wind power farm industry, as well as for special purpose ships (including military applications). In the water areas of the Baltic Sea, North Sea, and Mediterranean Sea, which are characterised by a short and steep wave, the hull shape has a substantial impact on the operational capacity and propulsion efficiency of the ship, as well as on comfort and safety of navigation. The article analyses selected aspects of seakeeping for four variants of a selected case study vessel, indicating practical limitations of the strip method. The analysed aspects included hull heaving and pitching, added resistance, Motion Thickness Indicator (MSI), and Subjective Magnitude (SM). Experimental tests were also performed in the towing tank. Their comparison with the numerical results has indicated high inaccuracy of the strip method. What is more, the simplified representation of hull shape used in the strip method makes it impossible to analyse the effect of hull shape changes on the predicted seakeeping characteristics. Especially for the case of head wave, neglecting highly non-linear phenomena, such as slamming or head wave breaking, in strip method-based computer simulations will significantly decrease the reliability of the obtained results. When using the strip method, the seakeeping analysis should be complemented with model tests in a towing tank, or by another more complex numerical analysis, such as CFD for instance.
\end{abstract}

Keywords: Ship design, seakeeping, ship motion, added resistance, towing tank, strip theory

\section{INTRODUCTION}

The ship sailing on the sea is subject to the action of sea waves being the source of many undesirable phenomena. A direct effect of this action is ship motion in six degrees of freedom, which provokes such events as green water shipping and/or propeller emerging, along with additional dynamic loads and accelerations acting on the hull, thus increasing its resistance. These phenomena considerably reduce the ship's operability and propeller efficiency, decrease the living comfort of the crew and passengers, and increase the risk of damage to the propeller, hull, and/or the transported cargo. The ship response to the action of sea waves is referred to as "seakeeping performance" and is a characteristic property of the ship [1]. For the time being, there are no criteria applicable in design work which would unambiguously characterise the ship as that with great seakeeping performance. Based on their legislative classification, the existing requirements can be divided into a number of groups. The first group includes non-normative requirements, such as operational and comfort criteria, related with physical properties of the ship. The operational criteria are described by accelerations at a given point of the hull, amplitudes of pitching, and the probability of appearance of slamming and green water shipping phenomena [2], [3], [4], [5]. The comfort criteria are expressed by the Motion Sickness Indicator (MSI) [6] and the Subjective Magnitude (SM). The acceptable values of these indicators have been obtained from experimental 
tests of human responses to ship motions caused by sea waves. The next group of criteria applicable in assessing the seakeeping performance of the ship comprise normative requirements described in publications but not taken into account by classification societies [6], [7], [8]. Most of these criteria coincide with the non-normative requirements. In contrast, the normative requirements expressed in the regulations of classification societies focus on the comfort of crew and passengers on the ship, and mainly refer to vibration related phenomena [9], [10], [11] or the safety of transported cargo, which is controlled, for instance, by assigning limits to forces acting in the container anchorage system [12]. The last group of design criteria comprises IMO recommendations, which mainly focus on ship manoeuvrability [13], avoiding dangers in unfavourable weather conditions [14], and energy efficiency of the ship, expressed by the Energy Efficiency Design Index (EEDI) [15], [47]. Unfortunately, all these criteria are formulated in the way which considerably limits their direct practical use at the hull shape design stage. To be more applicable, these criteria should refer to parameters directly related with the geometric shape of the hull and the mass distribution in the designed ship, i.e. the parameters which can be used as variables in design equations. This requirement is most closely met in a combined system of nonnormative and normative non-classification requirements given in NATO norms for warships [7].

Recently, new design solutions of ship hull bow section have been developed in the shipbuilding industry to improve seakeeping characteristics of the ship. One of these solutions, being the result of cooperation of Delft University and Damen Shipyard, employs the results of investigations of the effect of hull length extension on ship performance, often referred to as Enlarged Ship Concept (ESC). As a result of these investigations, the concept of AXE-bow has been developed [16], [17], [18], in which the ship length is significantly increased, while preserving all remaining technical parameters, such as breadth, speed, cargo carrying capacity, and functionality. This approach improves significantly the resistance and seakeeping characteristics, at relatively moderate increase of construction cost [16], [18]. The designed bow has a very narrow $\mathrm{V}$-shape, with displacement changes as small as possible when the bow moves up and down in the water during heaving and pitching motions. According to the linear strip theory [19], in which the bow section is modelled as the mass-spring system, reducing the stiffness of the system should, theoretically, reduce the vertical accelerations in the bow section as a result of the decrease of pitching amplitude. However, the results of experimental tests in the towing tank have revealed that the pitching amplitudes increase, with simultaneous amplitude decrease of maximum vertical acceleration peaks by about 50\% [18]. Higher pitching amplitudes made the underwater hull part extend much deeper into water to avoid the slamming effect. At the same time, the bow part above the water level was lifted higher to avoid green water shipping. The total ship response to the action of sea waves was the effect of undefined nonlinearities. Another hull form, based on the so-called inverted bow design concept, has been introduced on the ship AHTS Bourbon Orca by the Norwegian company Ulstein in 2005 [20]. This bow type, having the commercial name of $\mathrm{X}$-bow, has a characteristic slope towards stern, which starts at the most extreme stem point, as well as narrow $\mathrm{V}$-shaped frames and smooth volume distribution in the bow section. This design is intended to decrease the added resistance of the hull and to reduce dynamic pressures generated by wave breaking. However, in both the AXE-bow and X-bow designs, the decreased displacement of the bow section leads to the increase of pitching and heaving amplitudes, with the resulting amplitude increase of vertical accelerations [16], [21]. The inverted bow concept was also analysed in [22] for frigate FFG-7. The tests performed in the model basin have shown the advantage of the new bow shape over its conventional counterpart. The added resistance was significantly reduced, also hull motions and accelerations caused by sea waves were smaller. Another interesting design is the wave-piercing hull. At present, this hull form is frequently used in shipbuilding, mostly as a result of the involvement of industrial partners in research activities. These hulls pierce the water surface smoothly with the bow section when sailing on both calm and wavy waters, which contributes to the appearance of many favourable effects. The crucial effect here is the decrease of hull resistance, with the resulting decrease of fuel consumption. For many vessels, rescue ships in particular, of high importance is also small decrease of ship speed on wavy waters. Other advantages of the abovenamed bow shapes include reducing the scale of slamming and green water shipping phenomena, along with the reduction of ship hull vibrations and accelerations. All these properties are part of ship's seakeeping and are relatively difficult to assess at ship design stage. For centuries, the shape of ship hull was subject to changes introduced mainly based on an evolutionary approach. These changes were introduced slowly and gradually, due to the lack of adequate tools for reliable prediction of the effect of hull shape change on the resulting ship's seakeeping. This approach has many advantages, the most important of which is that the risk to make a big design error is substantially reduced. At the same time, its basic disadvantage is that the majority of elements composing the new design is copied from previous forms. This results in rejecting radical changes, which would radically improve (or worsen) the ship seakeeping performance. The current rate of changes taking place in the maritime industry, along with the use of modern advanced computer tools, make it possible to apply a radical, revolutionary approach. In recent years, dynamic grow of computer techniques has been observed in both hardware and software areas. The effect of radical hull shape changes can be analysed using computer simulations (strip or panel methods, CFD) [45]. The obtained research data can be used to increase the ship propulsion efficiency, and improve the safety and comfort of ship operation [26], [52], [53], [54], [55], [56]. However, bearing in mind enormous cost of shipbuilding, the predicted seakeeping characteristics obtained from numerical analyses for the ship to be built should be finally verified using experimental methods (in 
the towing tank, for instance). As a rule, for the majority of ships, the range of hydrodynamic verification is still limited to calm water resistance tests, while the ship seakeeping characteristics are most frequently determined only using numerical methods, in particular the strip method, which is very efficient and popular in design offices [19], [23], [24]. The limited amount of publications analysing the effect of hull shape on ship's seakeeping makes that the real applicability of tools with the implemented strip methods in ship design is difficult to assess. On the one hand, the strip methods can be used for predicting selected parameters of ship seakeeping; for instance, they make it possible to assess whether the calculated value of Motion Sickness Index (MSI) meets the requirements. On the other hand, we should be aware that certain limitations of the strip method and their effect on the obtained results make this numerical method hardly adequate as an independent tool for predicting seakeeping performance. This article is intended to fill partially this gap by presenting the practical seakeeping analysis for a selected case study vessel. Indeed, in [16] the author has already shown that the linear strip method is not applicable for analysing seakeeping of fast single hull vessels, due to strong nonlinear phenomena. The present article also analyses a single hull vessel, along with the expected non-linear effects (wave breaking or splitting), but this vessel operates at forward speeds typical for displacement ships and in the presence of waves having length close to that of the ship.

\section{AIM AND SCOPE}

The research reported in the article analyses selected aspects of seakeeping for a case study vessel in four variants, indicating practical limits of the strip method.

An important cognitive aspect of the article is determining relative differences between results obtained from the strip method and the experimental test performed in the towing tank. In the strip method, the hull shape is not represented directly - it has a simplified form of a set of frame sections, which limits the effect of hull shape changes on seakeeping characteristics. What is more, especially for a head wave, it contains no information about the effect of nonlinear phenomena, in particular wave splitting or breaking, which occur in rough sea conditions. The results obtained using the strip method are expected to differ much from the experiment, as a direct result of the abovenamed limitations of this method.

The scope of the research comprised numerical calculations performed using the strip method as a standard computer tool commonly used in design offices. The object of the analysis was the vessel Nawigator XXI, having a traditional V-shaped bow with a bulbous bow attached. The research programme included defining applicable evaluation criteria, and then performing computer simulations of seakeeping performance, complemented by experimental tests in the towing tank. A number of possible hull forms were selected to redesign the original hull of the vessel to the form having potential for seakeeping improvement. The hull shape concepts were selected from the most innovative solutions used in shipbuilding industry - similar to AXE-bow and X-bow types. Included are the detailed results of the strip method-based analysis of the effect of changes in the vessel design on hull resistance, added resistance, hull motions (heaving, pitching), accelerations, and SM and MSI coefficients.

\section{OBJECT OF RESEARCH - CASE STUDY VESSEL}

The object of the research was $\mathrm{m} / \mathrm{v}$ Nawigator XXI (IMO 9161247), a modern research/training ship having the overall length $\mathrm{LOA}=60,3 \mathrm{~m}$. The ship hull has a maritime character. Its bow section has a commonly used V-shape, with bulbous lower part (Fig. 1). In the midship section, the ship has frame sections with vertical sides creating a cylindrical insert, while in the stern section, the hull has a characteristic inflection line of frame sections, situated above the waterline. The bodylines of the ship hull are shown in Fig. 2. The operational speed of the ship is 11 knots $\left(F_{N}=0,23\right.$; (moderate-speed ship). The ship is equipped with a Diesel engine of rated power $1120 \mathrm{~kW}$, with reduction gear and single controllable-pitch propeller propulsion system.

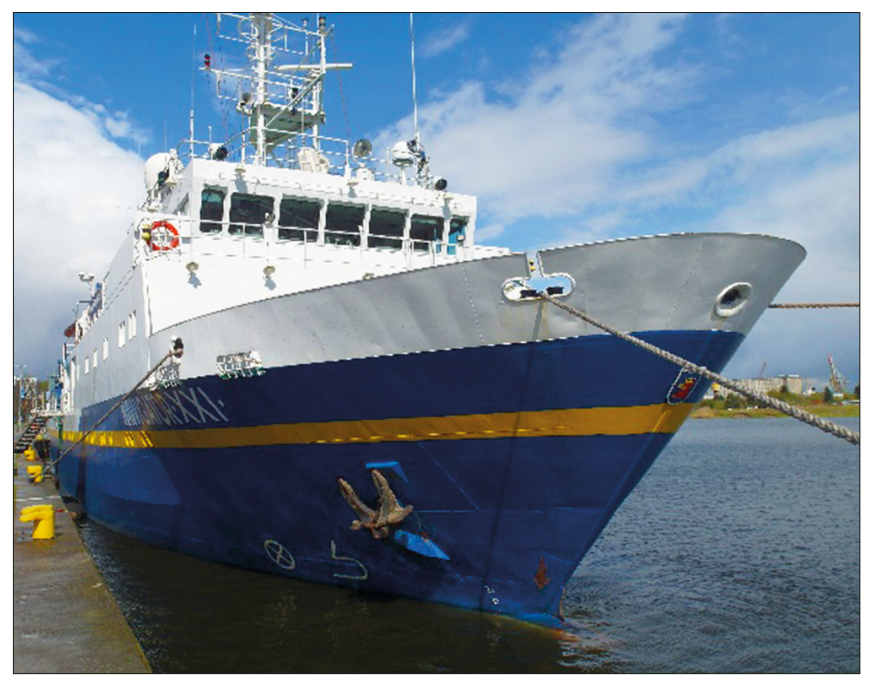

Fig. 1. Photo of the case study vessel $m / v$ Nawigator XXI (IMO 9161247)

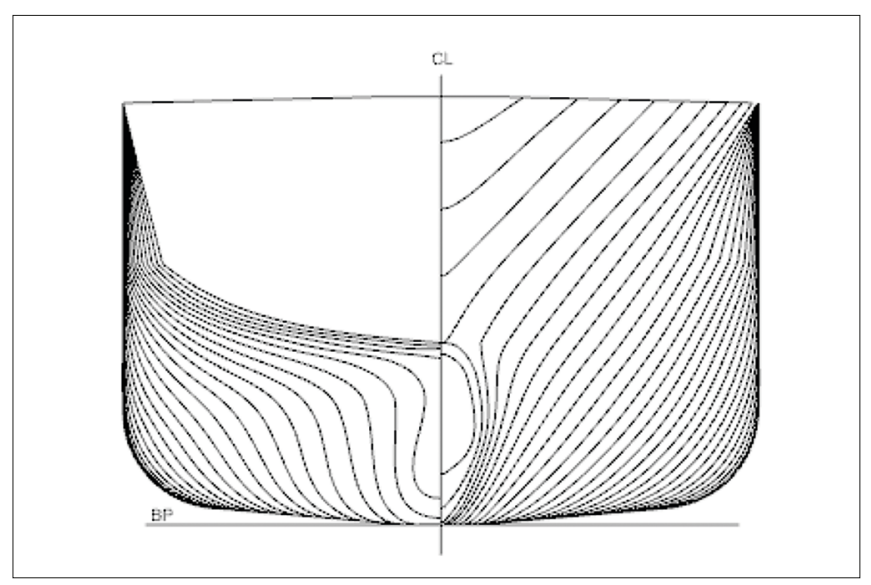

Fig. 2. Body lines of the case study vessel $m / v$ Nawigator XXI (IMO 9161247) 
In computer simulations, two cases were analysed which represented two different hull draught states. The first case corresponded to the operational state of the ship and took into consideration real mass distribution in which the ship had a slight trim by the stern. This is the real operating condition of the ship. The second analysed loading state corresponded to the calculated state of equilibrium for the following conditions: real displacement (identical as in case 1) and zero trim of the ship. This latter case required moving the position of ship's centre of gravity towards bow. The former loading state was used in seakeeping calculations, while the latter one was defined to analyse the calm water hull resistance. The resistance analysis is, as a rule, performed using the regression method, for which the ship is positioned evenly on the keel.

To determine mass characteristics, a detailed survey of masses on the real ship was done. The draughts were determined based on readings of marks on the hull. The filling condition of tanks was measured. After cataloguing the remaining deadweight capacity components, unit masses were calculated, along with the positions of their centre of gravity. The mass of the empty ship was calculated based on the available stability documentation, which included a report from the inclining test [27], among other data. In the article, the case study vessel in the version in which it was really built is marked N21. The remaining versions, marked AxeD, AxeL, and $\mathrm{X}$, were obtained by redesigning the original vessel to improve its seakeeping performance. The redesigning process is described in the next section, and the main hydrostatic parameters of all analysed vessel hull geometry variants are given in Table 1 .

\section{VARIANTS OF VESSEL HULL GEOMETRY}

In the article, selected seakeeping properties were determined for different variants of vessel hull geometry designs. For this purpose, the bow section of the vessel was redesigned from the traditional form (with V-shaped frames) to new, innovative forms. The redesigning process was done using a revolutionary approach, by introducing radically different bow forms in place of the existing one. To demonstrate the sole effect of bow section form change, the main geometric parameters of the hull were left the same as in the original variant. For the $\mathrm{X}$ variant, the hull redesigning to the new form was done preserving the following parameters: length between perpendiculars, breadth, draught, midship section, length of cylindrical insert, displacement, and longitudinal position of the centre of buoyancy $\left(\mathrm{L}_{\mathrm{CB}}\right)$. For the Axe concept, simultaneous preservation of vessel's length and displacement was impossible, due to certain specificity of this hull form. Therefore, two variants were designed in this case one variant preserving the hull waterline length, while the other preserving the displacement of the original vessel N21. In the bow section, it was the distribution of volumes in vessel's longitudinal and vertical directions which was the object of changes. The shape redesigning was done in the Model Center package offered by Phoenix, using the parametric modelling technique $\mathrm{CAD}$ and the optimisation technique. As the first step, the shapes were reconstructed and parametrised based on patent documentations of the Axe-bow shape developed by Damen [28], and the X-bow shape developed by Ulstein [29]. Then, the values of parameters controlling the longitudinal and transverse distribution of volumes were changed iteratively to obtain the displacement equal to that of the vessel N21, while preserving its length, draught, breadth, and constant frame cross-section in the area of cylindrical hull insert. The result of the above redesigning activity was a family of four shapes: the basic hull, marked as N21, the hull with Axe bow preserving constant displacement, marked as AxeD, the hull with Axe bow preserving constant hull length between perpendiculars, marked as AxeL, and the hull with bow section similar to X-bow, marked as X. For the AxeD variant, to preserve its displacement the length of the vessel was increased, which was in line with the concept of improving the seakeeping performance by extending the hull waterline [30]. The variant marked as AxeL preserves constant length at reduced displacement for constant design draught. These two variants are characterised by the decrease of block coefficients CB and CP. For the variant marked AxeD, the wetted area of the hull significantly increased. Table 1 [next page] collates main parameters of all analysed variants for even-keel sailing and for the average operating state (with trim 0,5 degrees to the stern).

Programme of examination of seakeeping performance of case study vessel The below described examination programme included defining comparison criteria, described in Section 5.1, which were then used to analyse the seakeeping performance of the vessel. In Section 5.2, the applied numerical methods are named, while in Section 5.3 , the sea wave load conditions are described for which the examination was performed. Additionally, to compare the numerical results with the experiment, the experimental tests were performed in the model basin, as described in Section 6 .

\section{COMPARISON CRITERIA}

The following comparison criteria were adopted:

- bare-hull resistance,

- heave RAO,

- pitch RAO,

- added resistance,

- accelerations at forward perpendicular (aPD). The location, at the bow deck level of Nawigator XXI ( $\mathrm{x}=54,13 \mathrm{~m}$ od PR, $\mathrm{z}=7,05 \mathrm{~m}$ above PP), was assumed the same for all cases - Subjective Magnitude SM,

- Motion Sickness Index MSI.

\section{NUMERICAL METHODS}

The seakeeping performance analysis of the vessel was performed using the strip theory-based numerical method developed by Salvesen [25], which was implemented in the Maxsurf v 21 software [8]. The strip method, which is in frequent use in design offices, is also used in publications 
Tab. 1. Hydrostatic parameters of case study vessel variants

\begin{tabular}{|c|c|c|c|c|c|c|c|c|c|}
\hline \multirow{5}{*}{ Name } & \multirow{5}{*}{ Unit } & \multicolumn{8}{|c|}{ Hull form } \\
\hline & & \multicolumn{2}{|c|}{$\mathrm{N} 21$} & \multicolumn{2}{|c|}{ AxeD } & \multicolumn{2}{|c|}{ AxeL } & \multicolumn{2}{|c|}{$\mathrm{X}$} \\
\hline & & & & & & & & $\Rightarrow$ & \\
\hline & & \multicolumn{8}{|c|}{ Value } \\
\hline & & $\begin{array}{l}\text { Trim } \\
0 \text { deg }\end{array}$ & $\begin{array}{c}\text { Trim } \\
0.5 \mathrm{deg}\end{array}$ & $\begin{array}{l}\text { Trim } \\
0 \text { deg }\end{array}$ & $\begin{array}{c}\text { Trim } \\
0.5 \mathrm{deg}\end{array}$ & $\begin{array}{l}\text { Trim } \\
0 \text { deg }\end{array}$ & $\begin{array}{c}\text { Trim } \\
0.5 \mathrm{deg}\end{array}$ & $\begin{array}{l}\text { Trim } \\
0 \text { deg }\end{array}$ & $\begin{array}{c}\text { Trim } \\
0.5 \mathrm{deg}\end{array}$ \\
\hline Displacement & $\mathrm{t}$ & 1141 & 1137 & 1142 & 1144 & 1022 & 1020 & 1141 & 1137 \\
\hline Volume (displaced) & $\mathrm{m}^{3}$ & 1113 & 1109 & 1114 & 1116 & 997 & 995 & 1113 & 1109 \\
\hline Draft at AP & $\mathrm{m}$ & 3.150 & 3,35 & 3,150 & 3,386 & 3,150 & 3,35 & 3,150 & 3,35 \\
\hline Draft Amidships & $\mathrm{m}$ & 3,150 & 3,125 & 3,150 & 3,125 & 3,150 & 3,125 & 3,150 & 3,125 \\
\hline Trim (+ve by stern) & $\mathrm{m}$ & 0,000 & 0,45 & 0,000 & 0,522 & 0,000 & 0,449 & 0,000 & 0,450 \\
\hline Trim angle (+ve by stern) & deg & 0,0 & 0,467 & 0,0 & 0,467 & 0,0 & 0,4674 & 0,0 & 0,467 \\
\hline Immersed depth & $\mathrm{m}$ & 3,150 & 3,300 & 4,182 & 3,917 & 4,143 & 3,911 & 3,151 & 3,292 \\
\hline WL Length & $\mathrm{m}$ & 55,16 & 55,68 & 63,93 & 63,96 & 55,08 & 55,10 & 55,15 & 55,10 \\
\hline Beam max extents on WL & $\mathrm{m}$ & 10,5 & 10,5 & 10,5 & 10,5 & 10,5 & 10,5 & 10,5 & 10,5 \\
\hline Wetted area & $\mathrm{m}^{2}$ & 663 & 667 & 730 & 734 & 637 & 641 & 647 & 652 \\
\hline Max sect. area & $\mathrm{m}^{2}$ & 30,4 & 30,4 & 30,3 & 30,8 & 30,3 & 30,4 & 30,3 & 30,4 \\
\hline Waterpl. Area & $\mathrm{m}^{2}$ & 466 & 473 & 510 & 516 & 446 & 452 & 457 & 465 \\
\hline Prismatic coeff. (Cp) & - & 0,667 & 0,654 & 0,575 & 0,567 & 0,598 & 0,593 & 0,665 & 0,662 \\
\hline Max sect. coeff. $(\mathrm{Cm})$ & - & 0,916 & 0,915 & 0,916 & 0,916 & 0,916 & 0,914 & 0,917 & 0,912 \\
\hline Waterpl. coeff. (Cwp) & - & 0,805 & 0,809 & 0,760 & 0,768 & 0,771 & 0,782 & 0,789 & 0,805 \\
\hline LCB length & $\mathrm{m}$ & 26,64 & 26,01 & 27,86 & 26,96 & 25,15 & 24,49 & 26,43 & 25,82 \\
\hline LCF length & $\mathrm{m}$ & 25,32 & 24,67 & 27,80 & 26,95 & 24,47 & 23,81 & 24,87 & 24,27 \\
\hline
\end{tabular}

for assessing seakeeping performance of vessels, see [31], [32] for instance. The added resistance was determined using the Havelock method [33], while the calm water resistance of the vessel was determined using the Holtrop-Mennen (H-M) method [34], [35], [48]. Subjective Magnitude (SM) was calculated in accordance with [19], and the Motion Sickness Index (MSI) in accordance with relevant norms [36], [37].

\section{ASSUMPTIONS CONCERNING CALCULATION CASES}

When determining selected seakeeping properties of the vessel, the wave of significant height of $\mathrm{H}_{1 / 3}=1,6 \mathrm{~m}$ was assumed with two characteristic periods, $\mathrm{T}_{\mathrm{p}}=4,8 \mathrm{~s}$ and $\mathrm{T}_{\mathrm{p}}=6.5 \mathrm{~s}$, which corresponded to weather conditions most often occurring in the Baltic Sea and partially in the North Sea [1]. The calculations made use of the irregular wave model and the JONSWAP wave spectrum [38]. The vessel speed assumed in the calm water calculations ranged between 3 and 13 knots, while the seakeeping performance calculations were performed for the speed of: 9.1 knots $(\mathrm{Fn}=0,20), 10,4$ knots $(\mathrm{Fn}=0,23), 11,7$ knots $(\mathrm{Fn}=0,26)$, and 13 knots $(\mathrm{Fn}=0,29)$. For all cases, both in numerical calculations and experimental tests, the assumed wave related vessel motion corresponded to the head wave.

\section{MODEL TESTS IN A TOWING TANK}

To compare the predictions obtained from the numerical strip method-based analysis, experimental tests were performed in the towing tank owned by Gdansk University of Technology, Faculty of Ocean Engineering and Ship Technology. Generally, model tests still provide most reliable results of vessel seakeeping performance and make it possible to verify the correctness of the designed hull shape [39]. However, bearing in mind relatively long time and high cost of physical model manufacturing, a decision was made to perform experimental tests only for the vessel Nawigator XXI with the bow shape in the "as-built" version. The tests were performed in the 
conditions described above in the examination programme, i.e. calm-water conditions for resistance tests, and wavy water (regular head wave) for seakeeping examination. The wave tests included the measurements of resistance increase, amplitudes of motions (heaving, pitching), and vertical accelerations at forward perpendicular, which determined amplitude characteristics for the assumed vessel advance speeds, and wave amplitudes and frequencies.

\section{MODEL FOR EXPERIMENTAL TESTS IN TOWING TANK; MEASURING EQUIPMENT USED}

In the experimental tests, use was made of geometrically similar model vessel in scale 1:25 - see Fig. 3 . The basic parameters of the model are given in Table 2. The tests were performed in the towing tank of $40 \mathrm{~m}$ in length, $4 \mathrm{~m}$ in breadth, and $3 \mathrm{~m}$ in depth. The tank is equipped with a towing carriage, a wave generator, and a beach for wave attenuation. The measuring equipment ensures recording wave height and model vessel motions with frequency of $500 \mathrm{~Hz}$. The tests were performed in accordance with the ITTC procedure [40], and the measurement uncertainty of the recorded data, calculated in accordance with [41], did not exceed $2.5 \%$. The model was fastened to the carriage in a way which preserved two degrees of freedom (heaving and pitching). The model vessel prepared for tests is shown in Fig. 3.

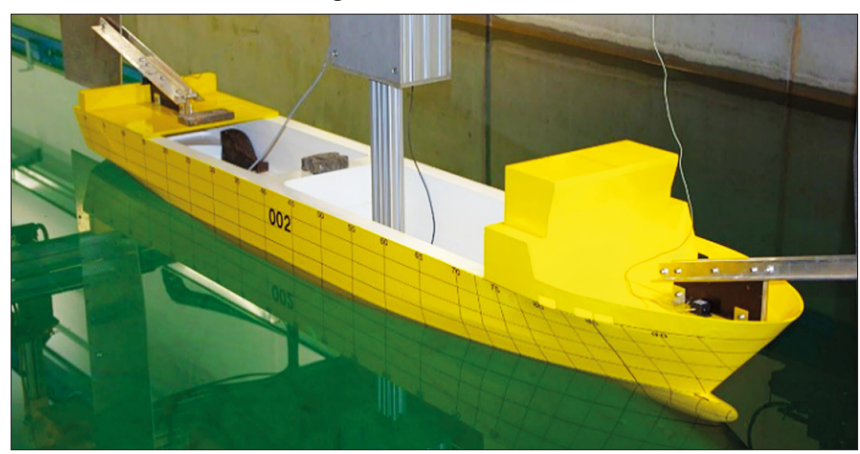

Fig. 3. Model of the case study vessel N21 in towing tank Tab. 2. Basic parameters of model vessel used in towing tank tests

\begin{tabular}{|c|c|c|c|}
\hline Name & Symbol & Value & unit \\
\hline Length & $\mathrm{L}$ & 2,408 & $\mathrm{~m}$ \\
\hline Breadth & $\mathrm{B}$ & 0,420 & $\mathrm{~m}$ \\
\hline Length of waterline & $\mathrm{L}_{\mathrm{WL}}$ & 2,227 & $\mathrm{~m}$ \\
\hline Draught at FP & $\mathrm{T}_{\mathrm{FP}}$ & 0,116 & $\mathrm{~m}$ \\
\hline Draught at AP & $\mathrm{T}_{\mathrm{AP}}$ & 0,134 & $\mathrm{~m}$ \\
\hline Displacement volume & $\mathrm{V}_{\mathrm{f}}$ & 0,071 & $\mathrm{~m}^{3}$ \\
\hline Wetted surface area & $\mathrm{S}_{\mathrm{S}}$ & 1,084 & $\mathrm{~m}^{2}$ \\
\hline
\end{tabular}

\section{RESULTS OF TESTS}

Firstly, the test results used for preparing the calm water hull resistance curve will be analysed, as these results will be then used for determining the added resistance. The results of calm water bare-hull resistance obtained for the vessel N21 in the model basin and from numerical calculations making use of the Holtrop-Mennen (H-M) method are compared in Fig. 4. The extrapolation of hull resistance results to the natural scale was made using the Prohaska $1+\mathrm{k}$ method [42]. This method is described in detail in [43], which also analyses the effect of selecting the extrapolation method of the obtained experimental results to the natural scale.

The obtained results have revealed that in the speed range up to 10,0 knots $\left(F_{n}=0,22\right)$, the relative difference between the results was approximately equal to $10 \%$. For higher speeds (exceeding $\mathrm{F}_{\mathrm{n}}=0,22$ ) this relative difference increases much and in the analysed range reached the maximum of $16 \%$ for vessel speed equal to $\mathrm{v}=13,0$ knots. The differences between the results obtained using different methods can be considered large. The uncertainty of the numerical results is caused by the assumptions of the $\mathrm{H}-\mathrm{M}$ regression method. Technically, the applicability range of this method includes the analysed model vessel, but this does not mean that it will give the results well coinciding with those measured in the towing tank. On the other hand, the uncertainty of the results extrapolated from the experimental measurements recorded in the towing tank can also be significant. As was shown in [43], assuming different friction resistance coefficients and the use of different methods to determine the hull shape coefficient leads to the total hull resistance results differing by $-6 \%$ to $11 \%$ from those measured in sea trials of a real vessel. In is noteworthy that these differences refer to different vessel speeds, and the higher the analysed speed, the larger the observed relative difference between the results obtained using different methods.

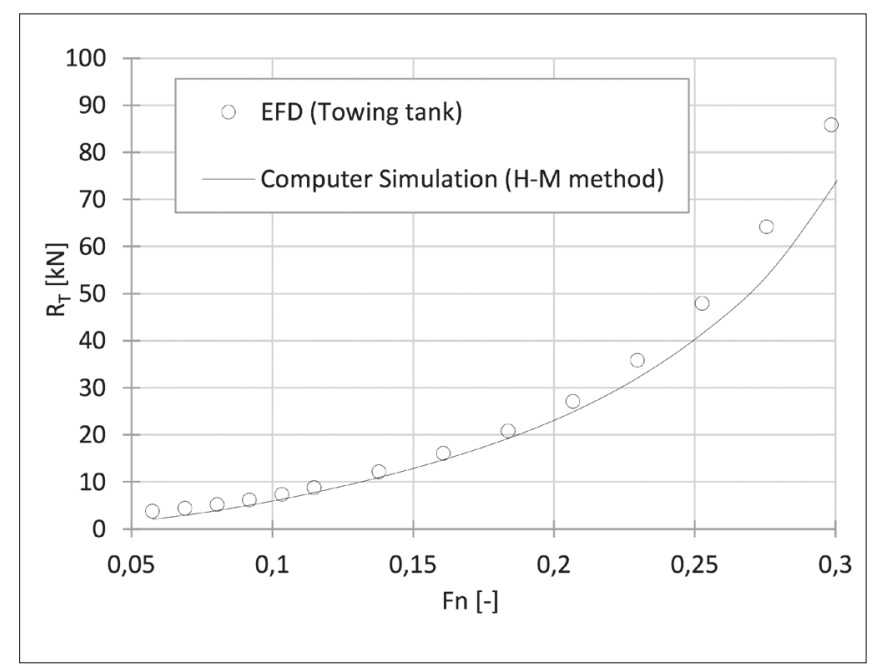

Fig. 4 Results of total calm water resistance of the hull, determined using the Holtrop-Mennen (H-M) method and recorded experimentally in the towing tank (EFD)

Fig. 5 and Fig. 6 compare the results of amplitude characteristics of heaving and pitching determined from computer simulations and experimental tests performed in the model basin. In the computer simulations, use was made of the Havelock method [33]. The head wave parameters were assumed based on the JONSWAP wave spectrum with period of $\mathrm{T}=4,79 \mathrm{~s}$ and height of $\mathrm{H}=1,6 \mathrm{~m}$, for the vessel speed ranging from 9,1 to 13 knots. 


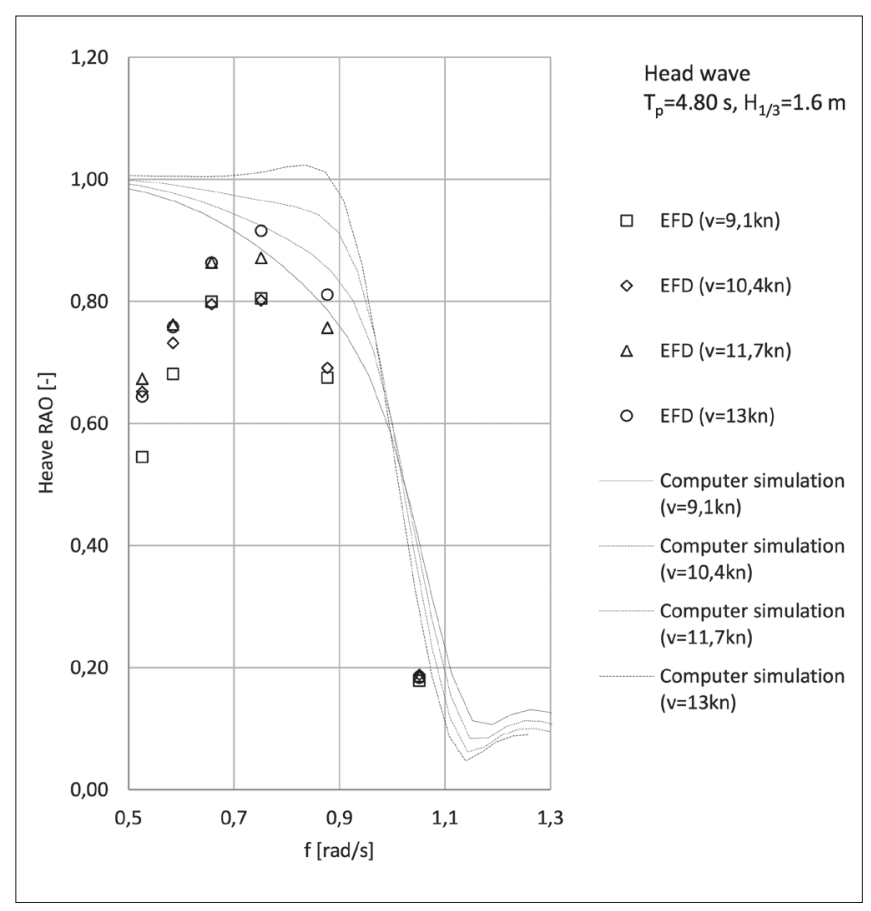

Fig. 5. Heave Response Amplitude Operator (RAO) for the vessel N21

The results of hull motions are shown in the dimensionless form of RAO functions. Relative differences between the numerical and experimental results in the wave frequency range of $0,7-1 \mathrm{rad} / \mathrm{s}$ differ from the expected values by o $10-15 \%$, with well predicted locations of resonance peaks.

Larger differences observed for wave frequencies below $0,7 \mathrm{rad} / \mathrm{s}$ and above $1 \mathrm{rad} / \mathrm{s}$ result from limitations of the linear model of the wave-vessel system, which preserves correctness within the wave frequency range from $\sqrt{\frac{L}{g}}$ to $5 \cdot \sqrt{\frac{L}{g}}$. Despite falling into the theoretical applicability range of the strip method, the obtained simulation results differ significantly from those obtained from experimental tests. For the wave frequency range below $0,7 \mathrm{rad} / \mathrm{s}$, the relative differences of the predicted hull motions amount to as much as $40 \%$ for heaving and $20 \%$ for pitching. It is noteworthy that the obtained differences of results are similar to those used as validation data for the Maxsurf software, the description of which is given as Appendix B in [8]. That analysis took into consideration mainly the results of experimental tests [49], [50], [51] and showed differences in hull motions ranging between $15 \%-70 \%$ for heaving and $5 \%-25 \%$ for pitching. Thus, the strip method describes hull motions on wave with rather high uncertainty, affected by a number of factors, such as wave parameters and vessel speed, for instance. The effect of these factors on the results is difficult to assess. In the present examination, the phenomenon of head wave breaking was clearly observed. This phenomenon had a significant effect on differences in heaving and pitching results obtained from the strip method, which neglects it, and the experiment, taking it fully into account.

The next analysed seakeeping performance criterion was the added resistance, i.e. the resistance resulting from the action of sea waves. For this criterion, the comparison of

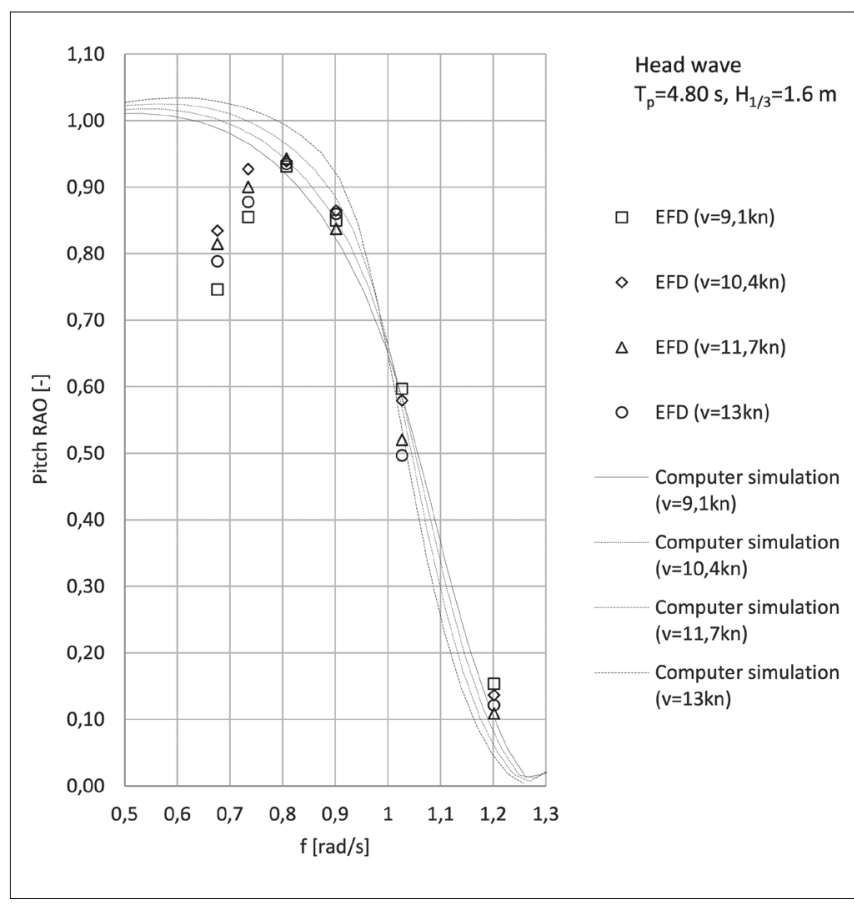

Fig. 6 Pitch Response Amplitude Operator (RAO) for the vessel N21

the numerical results with those obtained experimentally is shown in Fig. 7. The relative difference in added resistance values ranged from 1 to $20 \%$ and depended on vessel speed and wave frequency. Like for hull motion predictions, the observed large differences in predicting the added resistance with the aid of the above two methods resulted from the presence of head wave breaking phenomenon.

The next Chapter discusses the effect of bow redesigning on selected seakeeping properties of the case study vessel.

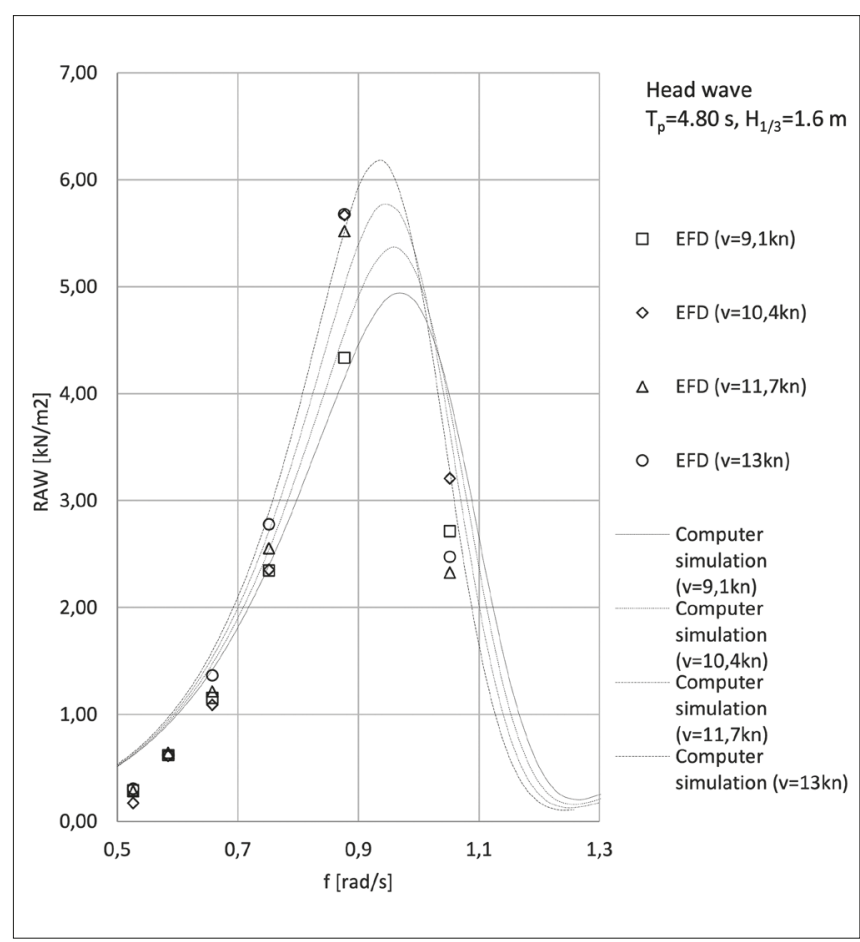

Fig. 7. Added resistance RAW for the vessel N21 


\section{ANALYSING SELECTED SEAKEEPING PROPERTIES OF THE CASE STUDY VESSEL}

In Section 7.2 below, the results of numerical analysis of case study vessel seakeeping are presented. To determine the added resistance, the calm water hull resistance was firstly calculated, as described in Section 7.1. The seakeeping analysis was performed for the vessel in variants described in Chapter 4 using the examination programme presented in Chapter 5.

\section{RESULTS OF CALM WATER TESTS}

The results of calm water hull resistance determined using the H-M method are shown in Fig. 8. Due to the fact that these results refer to only one vessel, although each examined vessel model differed by shape and hydrostatic parameters, the results are shown as functions of Froude number. Relative differences in hull resistance results depend significantly on the speed range being the subject of analysis. In the speed range from 3 to 5 knots $(\mathrm{Fn}=0,11)$, the resistance values determined for successive hull variants are close to each other. Differences between the resistance curves in the range from 5 knots $(\mathrm{Fn}=0,11)$ to 10 knots $(\mathrm{Fn}=0,22)$ result mainly from differences in friction resistance, the value of which is proportional to the wetted area of the hull. The AxeD shape, with the largest wetted area, negatively dominates over the remaining variants in the speed range in which the main component is the friction resistance (the resistance increase is about $10 \%)$. However, with the speed increase, this variant becomes most favourable, which results from much lower pressure resistance than that in other hull geometry variants. The X model, with decreased wetted area with respect to the base variant N21, turns out least favourable for higher speeds due to rapidly increasing wave resistance. The variants AxeL and N21 have similar resistance characteristics. Much larger relative differences in total hull resistance appear above the Froude number at which the contribution of wave resistance in the total resistance increases [44], i.e. approximately above 10 knots $(\mathrm{Fn}=0,22)$. In this range the pressure resistance component significantly increases. Relative differences between particular vessel hull variants are given in detail in Table 3.

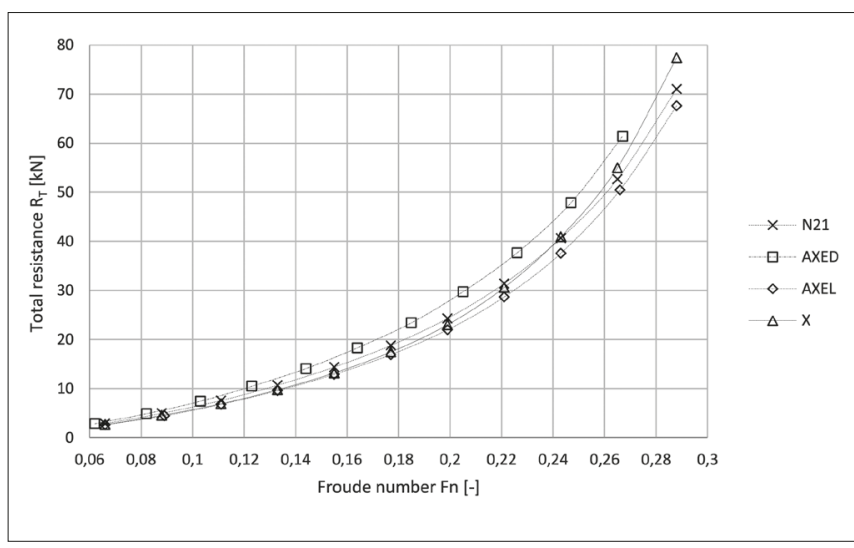

Fig. 8. Total calm water resistance calculated for the analysed hull forms
Tab. 3. Results of total calm water resistance for the vessel N21 and relative differences of resistance changes for ship variants AxeD, AxeL, and X, as compared to $\mathrm{N} 21$

\begin{tabular}{|c|c|c|c|c|}
\hline $\begin{array}{l}\text { Speed } \\
\text { [knots] }\end{array}$ & $\begin{array}{l}\mathrm{R}_{\mathrm{T}_{\mathrm{N} 21}} \\
{[\mathrm{kN}]}\end{array}$ & $\begin{array}{c}\text { Relative difference } \\
\text { between } \\
\text { AxeD and } \mathrm{N} 21 \\
\mathrm{R}_{\mathrm{T}_{\mathrm{N} 21}}-\mathrm{R}_{\mathrm{T}_{\mathrm{AxeD}}}\end{array}$ & $\begin{array}{c}\text { Relative difference } \\
\text { between } \\
\text { AxeL and } \mathrm{N} 21 \\
\mathrm{R}_{\mathrm{T}_{\mathrm{N} 21}}-\mathrm{R}_{\mathrm{T}_{\mathrm{AxeL}}}\end{array}$ & $\begin{array}{c}\text { Relative difference } \\
\text { between } \\
\mathrm{X} \text { and } \mathrm{N} 21 \\
\mathrm{R}_{\mathrm{T}_{\mathrm{N} 21}}-\mathrm{R}_{\mathrm{T}_{\mathrm{X}}}\end{array}$ \\
\hline & & $\begin{array}{c}\mathrm{R}_{\mathrm{T}_{\mathrm{N} 21}} \\
\cdot 100 \%\end{array}$ & $\begin{array}{l}\mathrm{R}_{\mathrm{T}_{\mathrm{N} 21}} \\
\cdot 100 \%\end{array}$ & $\begin{array}{l}\mathrm{R}_{\mathrm{T}_{\mathrm{N} 21}} \\
\cdot 100 \%\end{array}$ \\
\hline 3,0 & 2,9 & $-0,8 \%$ & $-10,1 \%$ & $-8,2 \%$ \\
\hline 4,0 & 4,9 & $-1,6 \%$ & $-11,1 \%$ & $-9,2 \%$ \\
\hline 5,0 & 7,6 & $-2,0 \%$ & $-11,5 \%$ & $-9,6 \%$ \\
\hline 6,0 & 10,7 & $-2,1 \%$ & $-11,6 \%$ & $-9,6 \%$ \\
\hline 7,0 & 14,4 & $-2,2 \%$ & $-11,5 \%$ & $-9,0 \%$ \\
\hline 8,0 & 18,8 & $-2,7 \%$ & $-11,1 \%$ & $-7,8 \%$ \\
\hline 9,0 & 24,3 & $-3,8 \%$ & $-10,5 \%$ & $-5,6 \%$ \\
\hline 10,0 & 31,4 & $-5,6 \%$ & $-9,5 \%$ & $-2,6 \%$ \\
\hline 11,0 & 40,6 & $-7,9 \%$ & $-8,2 \%$ & $0,7 \%$ \\
\hline 12,0 & 52,7 & $-10,1 \%$ & $-4,4 \%$ & $4,2 \%$ \\
\hline 13,0 & 71,0 & $-15,7 \%$ & $-5,0 \%$ & $8,3 \%$ \\
\hline
\end{tabular}

\section{RESULTS FOR HEAD WAVE}

The presented results of head wave seakeeping concern the vessel speed of $10,7 \mathrm{knots}$, i.e. the same as in the numerical model validation calculations described in Chapter 6. The computer simulations were performed for the wave with significant height $\mathrm{H}_{1 / 3}=1,6 \mathrm{~m}$ and two values of characteristic wave period. The first wave period, equal to $\mathrm{T}_{\mathrm{p}}=4,8 \mathrm{~s}$, corresponded to the characteristic period of waves on Baltic Sea waters [1], while the other one, equal to $\mathrm{T}_{\mathrm{p}}=6,5 \mathrm{~s}$, represented the characteristic wave period in the North Sea. It is noteworthy that in the calculations performed for the variant N21 discussed in Section 6, the maximum amplitude values in hull motions were recorded for the wave period $\mathrm{T}_{\mathrm{p}}=6,5 \mathrm{~s}$. The wave parameter values assumed in the calculations are given in Table 4 .

Tab. 4. Wave parameters

\begin{tabular}{|c|c|c|c|c|c|c|c|}
\hline \multirow[b]{2}{*}{ No. } & \multirow{2}{*}{ 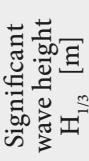 } & \multirow{2}{*}{ 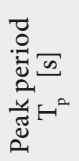 } & \multirow{2}{*}{ 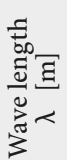 } & N21 & AxeD & AxeL & $\mathrm{X}$ \\
\hline & & & & \multicolumn{4}{|c|}{$\begin{array}{c}\lambda / \mathrm{L}_{\mathrm{WL}} \\
{[-]}\end{array}$} \\
\hline 1 & 1,6 & 4,8 & 35,8 & 0,64 & 0,56 & 0,65 & 0,65 \\
\hline 2 & 1,6 & 6,5 & 67,4 & 1,21 & 1,05 & 1,22 & 1,22 \\
\hline
\end{tabular}

To compare selected seakeeping properties of vessel variants with different bow shapes, the amplitude characteristics were calculated for heaving, pitching, and added resistance, along with Subjective Magnitude (SM) and Motion Sickness Index (MSI) values. The results of these calculations are shown in Fig. 9 - Fig. 14. For all analysed criteria, the differences between 
the results obtained for particular hull bow shape variants and the wave period $\mathrm{T}=4,8 \mathrm{~s}$ are smaller than their equivalents for wave period $\mathrm{T}=6,5 \mathrm{~s}$. In each analysed case, the variant N21 takes average values, while the variant AxeD presents most favourable properties. Only the accelerations at forward perpendicular for short wave are larger for this variant than for the remaining variants, but the differences are negligibly small. When adding up the calm water hull resistance and the added resistance generated by waves, the variant AxeD is also most favourable, especially when the vessel speed increases above 10 knots. Comparing the remaining two variants, AxeL and $\mathrm{X}$, we can conclude that differences between the results obtained for them are minimal, which results from certain limitations of the strip method, in which the hull shape is simplified and only represented by a set of frame sections. Only the use of more complex numerical methods, CFD for instance, provides opportunities for analysing the effect of bow shape changes [21]. What is more, the variant AxeL is an aberration of the Enlarged Ship Concept (ESC), as it changes the bow form by changing shapes of its frame sections, without extending
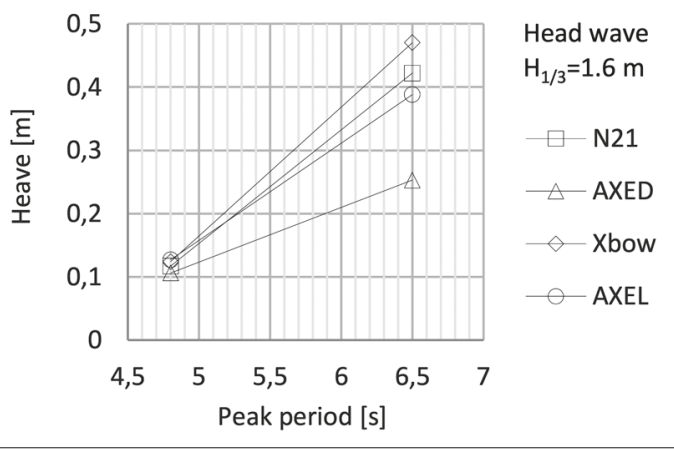

Fig. 9. Results of seakeeping analysis - Heave (RMS value)

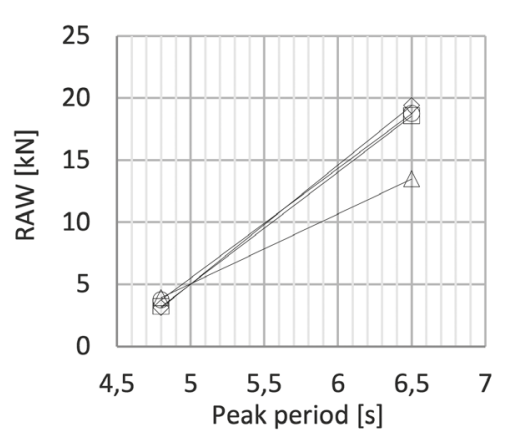

$$
\begin{aligned}
& \text { Head wave } \\
& \begin{array}{l}
\mathrm{H}_{1 / 3}=1.6 \mathrm{~m} \\
\square \text { N21 } \\
\triangle \text { AXED } \\
\diamond \text { Xbow } \\
\bigcirc \text { AXEL }
\end{array}
\end{aligned}
$$

Figure 11 Results of seakeeping analysis - Added resistance

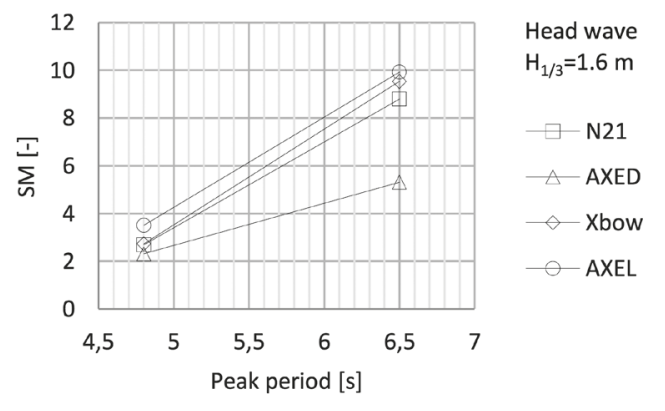

Fig. 13. Results of seakeeping analysis - Subjective Magnitude (SM) the entire hull body to preserve mass parameters. Only for heaving, a clear difference between these two variants can be observed. The variant $\mathrm{X}$ has the higher value of the transfer function. All numerical results of the analysed seakeeping properties for the selected vessel geometry variants are collated in Table 5 and Table 6 [next page].

It is noteworthy that all analysed hull shape variants have relatively high acceleration values at forward perpendicular. The maximum value of this parameter recommended in [7] is $0,4 \mathrm{~g}$. This value is exceeded in all variants, which leads to the worsening of comfort and safety. Moreover, for the long wave, $\mathrm{T}_{\mathrm{p}}=6,5 \mathrm{~s}$, the permissible values of Motion Sickness Index (MSI) are exceeded in all variants except AxeD. According to [7], to ensure the comfort of navigation, the MSI value should not exceed $20 \%$ for the time of exposure to accelerations equal to $4 \mathrm{~h}$. For the shorter wave, $\mathrm{T}_{\mathrm{p}}=4,8 \mathrm{~s}$, the MSI values calculated for all variants meet these requirements. The reference point in these MSI calculations was situated at the forward perpendicular, which means that it can be considered least favourable.

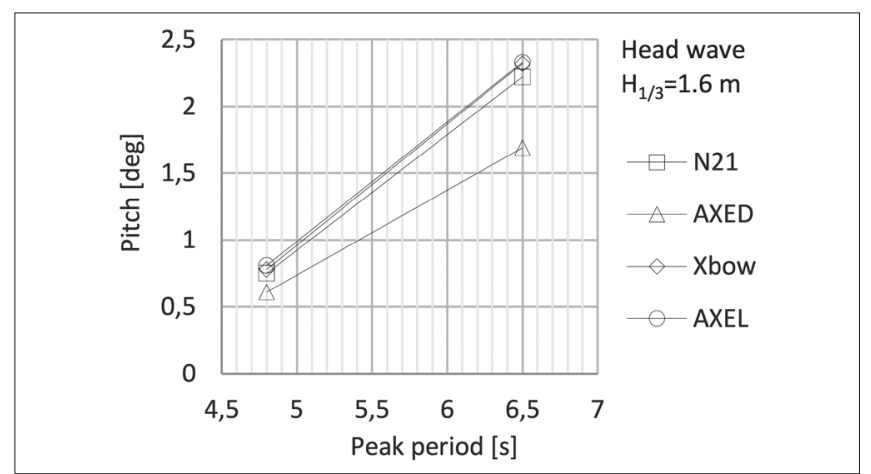

Fig. 10. Results of seakeeping analysis - Pitch (RMS value)

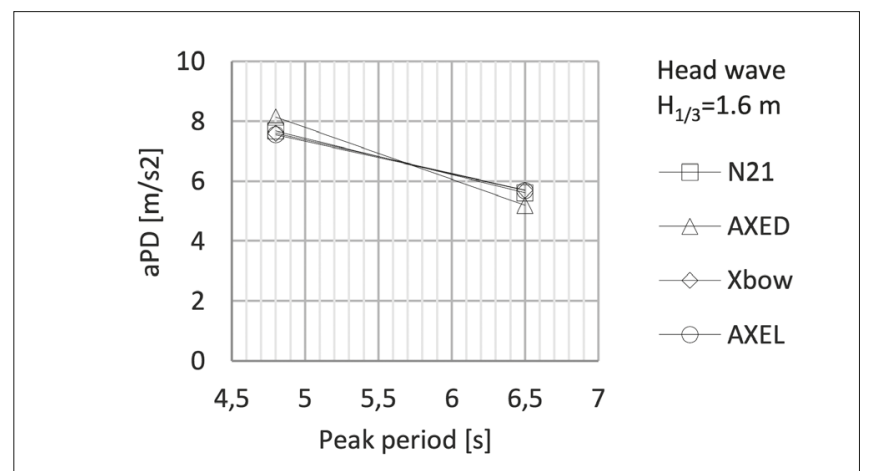

Fig. 12. Results of seakeeping analysis - Acceleration at FP

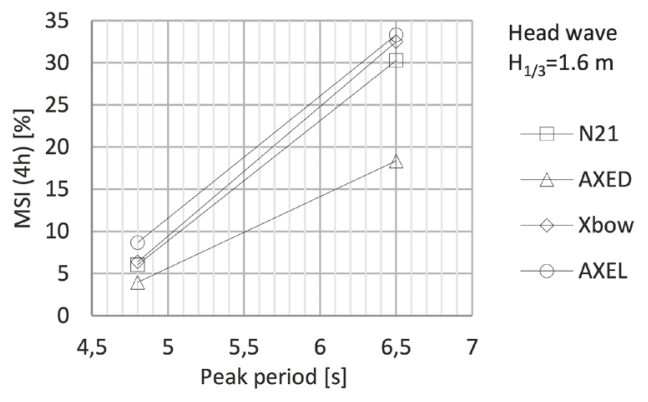

Fig. 14. Results of seakeeping analysis - Motion Sickness Index (MSI) 
Tab. 5. Results of case study vessel seakeeping analysis for wave $H_{1 / 3}=1,6 \mathrm{~m}$ and $T_{p}=4,8 \mathrm{~s}$

\begin{tabular}{|c|c|c|c|c|}
\hline & N21 & $\begin{array}{c}\text { Relative } \\
\text { difference } \\
\text { between } \\
\text { AxeD and } \\
\text { N21 }\end{array}$ & $\begin{array}{c}\text { Relative } \\
\text { difference } \\
\text { between } \\
\text { AxeL and } \\
\text { N21 }\end{array}$ & $\begin{array}{c}\text { Relative } \\
\text { difference } \\
\text { between } \\
\text { X and } \\
\text { N21 }\end{array}$ \\
\hline Heave [m] & 0,12 & $-10,4 \%$ & $7,9 \%$ & $5,6 \%$ \\
\hline Pitch [deg] & 0,75 & $-23,0 \%$ & $7,4 \%$ & $3,8 \%$ \\
\hline RAW [kN] & 3,19 & $18,4 \%$ & $14,5 \%$ & $-3,1 \%$ \\
\hline aPD [m/s'] & 7,67 & $5,8 \%$ & $-1,6 \%$ & $-0,9 \%$ \\
\hline SM [-] & 2,69 & $-16,2 \%$ & $23,4 \%$ & $1,4 \%$ \\
\hline MSI [\%] & 6,02 & $-52,7 \%$ & $30,4 \%$ & $5,3 \%$ \\
\hline
\end{tabular}

\section{SUMMARY AND CONCLUSIONS}

The seakeeping performance of a vessel is strongly affected by the hull shape, especially in its bow section. Good seakeeping is essential for small vessels navigating on Baltic Sea and North Sea waters, due to the presence of high and steep waves in these areas, with the wave length close to the vessel hull length.

The article presents the strip method-based analysis of selected seakeeping aspects for a case study vessel in four variants (N21, AxeD, AxeL, X). The application of the strip method is controversial. On the one hand, it is widely used in design offices to assess the seakeeping performance of the designed vessels, in particular to check whether the normative criteria, such as MSI for instance, are met. Due to its high efficiency, this method is presently the most often used commercial design tool. On the other hand, it is well known that this method makes use of a number of simplifying assumptions, including the hull shape representation by a number of frame sections, which reduces significantly its accuracy. Based on the analysis presented in the article, the following conclusions can be formulated:

1) Relatively large differences between the numerical results obtained using the strip method and those experimentally measured in the towing tank have been confirmed. The analysis was performed for the vessel variant N21, and relative differences of results between simulation and experiment amounted to about $10-15 \%$ for heaving and pitching in the wave frequency range of $0,7-1 \mathrm{rad} / \mathrm{s}$. For the ranges below 0,7 and above $1 \mathrm{rad} / \mathrm{s}$, the limitation of the linear model of the vessel-wave system was more visible, and these differences increased to $40 \%$ for heaving and to $20 \%$ for pitching. The relative differences in added resistance ranged between 1 and 20\%, depending on vessel speed and wave frequency. The observed differences result from simplifications used in the strip method. The obtained values of relative differences are close to those obtained from the Maxsurf validation analysis, see Appendix 2 in [8]. It is noteworthy that the present analysis was performed for a vessel having, theoretically, good seakeeping performance, and the phenomenon of head wave breaking was clearly observed in the experimental tests. This phenomenon,
Tab. 6. Results of case study vessel seakeeping analysis for wave $H_{1 / 3}=1,6 \mathrm{~m}$ and $T_{p}=6,5 \mathrm{~s}$

\begin{tabular}{|c|c|c|c|c|}
\hline & $\mathrm{N} 21$ & $\begin{array}{c}\text { Relative } \\
\text { difference } \\
\text { between } \\
\text { AxeD and } \\
\text { N21 }\end{array}$ & $\begin{array}{c}\text { Relative } \\
\text { difference } \\
\text { between } \\
\text { AxeL and } \\
\text { N21 }\end{array}$ & $\begin{array}{c}\text { Relative } \\
\text { difference } \\
\text { between } \\
\text { X and } \\
\text { N21 }\end{array}$ \\
\hline Heave [m] & 0,42 & $-66,8 \%$ & $-8,8 \%$ & $10,2 \%$ \\
\hline Pitch [deg] & 2,22 & $-31,4 \%$ & $4,7 \%$ & $4,3 \%$ \\
\hline RAW [kN] & 18,54 & $-37,6 \%$ & $1,1 \%$ & $4,4 \%$ \\
\hline aPD [m/s $\left.{ }^{2}\right]$ & 5,61 & $-8,0 \%$ & $1,4 \%$ & $1,5 \%$ \\
\hline SM [-] & 8,80 & $-65,6 \%$ & $11,4 \%$ & $7,8 \%$ \\
\hline MSI [\%] & 30,25 & $-64,9 \%$ & $9,1 \%$ & $6,9 \%$ \\
\hline
\end{tabular}

omitted in the strip method, has a great impact on vessel's seakeeping predictions.

2) Limited applicability of the strip method for analysing the effect of bow shape on vessel's seakeeping has been confirmed. The strip method reduces the geometric representation of the hull shape to a small number of frame sections. This is a relatively large model simplification, which makes it impossible to take into account nonlinear phenomena, such as head wave slamming or breaking, or green water shipping. When applying the strip method for vessel variants of the same length (N21, AxeL, X), the obtained relative differences in heaving, pitching, and added resistance were comparable with the order of uncertainty of the calculation method itself. For the variant $\mathrm{AxeD}$, with extended hull length, these differences were larger. Thus, the strip method does not provide opportunities for comparing results of seakeeping predictions for vessels of the same length and differing only by the hull form in bow section. 3) At the current state of knowledge, the use of the strip method as an independent tool for analysing seakeeping performance seems insufficient, and should be complemented with model tests, or more advanced computer simulations (CFD for instance). At present, the ship design regulations and norms related to the comfort and safety of humans (i.e. MSI) do not impose, nor limit methods which can be used for determining a vessel's response to the action of sea waves. This, in practice, results in the use of the most economically efficient method, which is the strip method. However, the further effect of this approach may be undesirable behaviour of the vessel in real operation. The authors of the article know of cases of vessels for which the MSI values calculated using the strip method met relevant normative requirements [6], but on which the safety and comfort of human existence were poor. It is also worth noting, that the current procedures of sea trials for ships do not include verification of any criteria concerning their seakeeping performance.

\section{ACKNOWLEDGEMENT}

This research was supported by the National Centre for Research and Development within the 'SmartPS' project ERA-NET MARTECII/SmartPS/4/2016. The research was 
supported by the Academic Computer Centre in Gdansk (CI TASK). All support is highly appreciated by the authors.

\section{REFERENCES}

1. J. Dudziak, Theory of ships (in Polish), Gdansk: Fundacja Promocji Przemysłu Okrętowego i Gospodarki Morskiej, 2008.

2. "The Nordic Cooperative Project: "Seakeeping Performance of Ship", Assessment of Ship Performance in a Seaway, Marintek," Norway, Trondheim, 1987.

3. T. Cepowski, Modelling of seakeeping qualities of open-top container carriers in the preliminary design phase. Polish Maritime Research 2(69) 2011 Vol 18; pp. 19-27

4. K. Sarioz and E. Narli, "Effect of criteria on seakeeping performance assessment," Ocean Engineering, p. 116101173, 25022005 .

5. I. Mudronja, P. Vidan, and J. Parunov, "Review of seakeeping criteria for container ship sustainable speed calculation in rough weather," Maritime Technology and Engineering, pp. 1059-1064, 2015.

6. B. Abeil, "Seakeeping Aspects in the Design of Survey Vessels," in ICSOT: Developments in Ship Design \& Construction, Ambon, 2012.

7. NATO, "NATO STANAG 4154, Common Procedures for Seakeeping in the Ship Design Process," 1997.

8. Bentley Systems, Motions Program \& User Manual, Bentley Systems, 2016.

9. ABS, Guide for passenger comfort on ship, Houston: American Bureau of Shipping, 2014.

10. DNV, Rules for Classification of Ships - Special Service and Type additional Class, Norway: Det Norske Veritas, 2009.

11. LR, Rules and Regulations for the Classification of Ships, United Kingdom: Lloyd's Register, 2016.

12. PRS, Publication No. 32/P - Requirements for Cargo Distribution and Fastening on Sea-going Vessels (in Polish), Gdansk: Polish Register of Shipping, 2015.

13. IMO, MEPC.1/CIrc.850/rev.1, 15 July 2015.

14. IMO, MSC.1/Circ.1228, 11 January 2007.

15. IMO, "Resolution MEPC.308(73) - Annex 5 - Guidelines on the method of calculation of the attained energy efficiency design index (EEDI) for new ships," 2018.
16. J. Gelling, "The Axe Bow: The Shape of Ships to Come," in 19th International HISWA Symposium on Yacht Design and Yacht Construction, Amsterdam, 2006.

17. J. L. Gelling and J. A. Keuning, "Recent Developments in the Design of Fast Ships," HISWA International Symposium on Yacht Design \& Construction, Vol. 5, July, pp. 57-68, 2010.

18. J. Keuning, J. Pinkster, and F. van Walree, "Further Investigation into the Hydrodynamic Performance of the AXE Bow Concept," in Proceedings of the 10th Symposium on High Speed, 2002.

19. A. R. J. M. Lloyd, Lloyd, Seakeeping - ship behaviour in rough weather, A R J M Lloyds, 26 Sprithead Avenue, Gosport, United Kingdom, 1989.

20. Ulstein, "X-BOW - how it started," 18 August, 2018. [Online]. Available: https://ulstein.com/innovations/x-bow. [Date of access: 25 November 2018].

21. K. Niklas and H. Pruszko, "Full scale CFD seakeeping simulations for case study ship redesigned from V-shaped bulbous bow to X-bow hull form," Applied Ocean Research, pp. 188-201, 2019, doi.org/10.1016/j.apor.2019.05.011.

22. J. K. White, "PhD Thesis: Numerical and experimental investigation of the effect of an inverted bow on the hydrodynamic performance of Navy combatant hull forms," Massachusetts Institute of Technology, 2015.

23. S. Hunt, "Comparison of experimental and analytical methods for optimization of seakeeping hull forms," in Hydrodynamics of High-Speed Craft, London, 1999.

24. A. Molland and D. Taunton, "Methods for assessing the seakeeping performance of competing high speed vessel designs," in Hydrodynamics of High-Speed Craft, London, 1999.

25. N. Salvesen, O. Tuck, and O. Faltinsen, "Ship motions and sea loads," Transactions, Society of Naval Architects and Marine Engineers, No. 78, pp. 250-287, 1970.

26. K. Niklas, "Supporting development of the smart ship technology by CFD simulation of ship behavior in close to real operational conditions," in Maritime Transportation and Harvesting of Sea Resources, Guedes Soares \& Teixeira, Red., London, Taylor \& Francis Group, 2018, pp. 535-540, ISBN 978-0-8153-7993-5.

27. T. Kolanek, J. Stęszewski, and J. Jarosz, "Record of experimental determination of vessel's centre of gravity position" (in Polish), Navicentrum sp. z o.o., Wrocław, 1997.

28. J. KEUNING, “EP 2038167 B1”. France 2010. 
29. Ulstein Design AS, "A Foreship Arrangement for a Vessel of the Deplacement Type". 2006.

30. J. Keuning and J. Pinkster, "Optimisation of the seakeeping behaviour of a fast monohull," in FAST'95 Third Int. Conference on Fast Sea Transportation, Lubeck, 1995.

31. T. Bunnik, E. Daalen, G. Kapsenberg, Y. Shin, R. Huijsmans, G. Deng, G. Delhommeau, M. Kashiwagi, and B. Beck, "A comparative study on state-of-art prediction tools for seakeeping," in 28th Symposium on Naval Hydrodynamics, California, 2010.

32. P. Sclavounos, D. Kring, Y. Huang, D. Mantzaris, S. Kim and Y. Kim, "A computational method as an advanced tool of ship hydrodynamic design," Transactions, Society of Naval Architects and Marine Engineers, No. 105, pp. 375-397, 1997.

33. T. Havelock, "Drifting Force on a Ship among Waves," Philosophical Magazine, No. 33, 1942.

34. J. Holtrop, "Statistical analysis of performance test results", Vol.24, No. 270, 1977.

35. J. Holtrop and G. Mennen, "An approximate power prediction method", 1982.

36. ISO 2631-3:1985, Evaluation of human exposure to wholebody vibration - Part 3: Evaluation of exposure to whole-body $z$-axis vertical vibration in the frequency range 0,1 to 0,63 $\mathrm{Hz}, 1985$.

37. BS 6841:1987, Guide to measurement and evaluation of human exposure to whole-body mechanical vibration and repeated shock, 1987.

38. F. Spiess, "Joint North Sea Wave Project (JONSWAP) Progress - An Observer's Report," Office of Naval Research London, London, 1975.

39. J. Michalski, Principles of ship design theory (in Polish), Gdansk: Wydawnictwo Politechniki Gdańskiej, 2013.

40. ITTC, "Recommended Procedures and Guidelines Resistance Test - 7.5-02-02-01”, ITTC, 2011.

41. ITTC, "Recommended Procedures and Guidelines: 7.502-02-02 General Guideline for Uncertainty Analysis in Resistance Tests", ITTC, 2014.

42. C. Prohaska, "A simple method for the evaluation of the form factor and the low speed wave resistance", in Proceedings of the 11th International Towing Tank Conference, ITTC'66, Tokyo, 1966.

43. K. Niklas and H. Pruszko, "Full-scale CFD simulations for the determination of ship resistance as a rational alternative method to towing tank experiments," Ocean Engineering, 2019, doi.org/10.1016/j.oceaneng.2019.106435.

44. A. Papanikolaou, Ship Design, Methodologies of Preliminary Design, London: Springer, 2014.

45. L. Larsson, F. Stern, and M. Visonneau, Numerical Ship Hydrodynamics, Springer, 2014.

46. IMO, "Guidelines for voluntary use of the ship energy efficiency operational indicator (EEOI)," IMO, 2009.

47. PRS, Publication No 103/P - Recommendations concerning energy efficiency of vessels (in Polish), PRS, Gdansk, 2014.

48. J. Holtrop, "A statistical resistance prediction method with a speed dependent form factor," in SMMSH'88, Varna, 1988.

49. J. Gerritsma, Ship motions in longitudinal waves. TNO Report No. 35S, Netherlands Research Centre TNO for Shipbuilding and Navigation, Delft, 1960.

50. J. Gerritsma, W. Beukelman, Comparison of calculated and measured heaving and pitching motions of a Series 60, $C B=0.70$, ship model in regular longitudinal waves. Report No. 142, Netherlands Ship Research Centre, Delft, 1966.

51. J.M.J. Journée, Verification and Validation of Ship Motions Program SEAWAY, Delft University of Technology Shiphydromechanics Laboratory Report1213a, 2001.

52. Henryk Olszewski and H. Ghaemi. New Concept of Numerical Ship Motion Modelling for Total Ship Operability Analysis by Integrating Ship and Environment Under One Overall System, Polish Maritime Research. 2018, Volume 25: Issue s1, doi.org/10.2478/pomr-2018-0020.

53. Zhiquan Liu. Adaptive Sliding Mode Control for Ship Autopilot with Speed Keeping. Polish Maritime Research. 2018, Volume 25: Issue 4, doi.org/10.2478/pomr-2018-0128.

54. Kaiye Hu, Yong Ding, and Hongwei Wang High-Speed Catamaran's Longitudinal Motion Attenuation with Active Hydrofoils, Polish Maritime Research, 2018, Volume 25: Issue s2, doi.org/10.2478/pomr-2018-0074.

55. Ang Li and Yunbo Li. Numerical and Experimental Study on Seakeeping Performance of a High-Speed Trimaran with T-foil in Head Waves, Polish Maritime Research, 2019, Volume 26: Issue 3, doi.org/10.2478/pomr-2019-0047.

56. W. Litwin, W. Leśniewski, D. Piątek, and K. Niklas, "Experimental Research on the Energy Efficiency of a Parallel Hybrid Drive for an Inland Ship," Energies, vol. 12, no. 9, p. 1675, 2019, doi: 10.3390/en12091675. 


\title{
CONTACT WITH THE AUTHORS
}

\author{
Karol Niklas \\ e-mail:karol.niklas@pg.edu.pl \\ Gdańsk University of Technology \\ Narutowicza 11/12, 80-233 Gdańsk \\ Poland \\ Artur Karczewski \\ e-mail:artkarcz@pg.gda.pl \\ Gdańsk University of Technology \\ Narutowicza 11/12, 80-233 Gdańsk \\ Poland
}

